\title{
Counseling, quality of life, and acute postoperative pain in elderly patients with hip fracture
}

\author{
This article was published in the following Dove Press journal: \\ Journal of Multidisciplinary Healthcare \\ 13 September 2013 \\ Number of times this article has been viewed
}

\author{
Maria Gambatesa' \\ Alessandro D'Ambrosio' \\ Davide D'Antini' \\ Lucia Mirabella' \\ Antonella De Capraris' \\ Salvatore luso ${ }^{2}$ \\ Antonello Bellomo ${ }^{2}$ \\ Antonio Macchiarola ${ }^{3}$ \\ Michele Dambrosio' \\ Gilda Cinnella' \\ 'Department of Anesthesiology \\ and Intensive Care, ${ }^{2}$ Department of \\ Psychology and Psychiatry, University \\ of Foggia, Foggia, Italy; ${ }^{3}$ Department \\ of Orthopedic and Trauma Surgery, \\ Riuniti Hospital, Foggia, Italy
}

Correspondence: Gilda Cinnella UO di Anestesia Rianimazione e Terapia Intensiva, Università di Foggia, Ospedale Maternità Via L Pinto, I, 7II 100 Foggia, Italy

Tel $+39088 \quad 1732387$

Fax +390881732387

Email g.cinnella@unifg.it
Introduction: Hip fractures represent one of the most important causes of morbidity and mortality in elderly people. Anxiety and depression affect their quality of life and increase pain severity, and have adverse effects on functional recovery. Recent World Health Organization guidelines emphasize that therapeutic regimes need to be individualized and combined with psychological support. This study was launched with the primary endpoint of assessing if and to what extent client-centered therapy affects the perception of pain, reduces anxiety and depression, and increases the quality of life of elderly patients with hip fracture.

Materials and methods: Forty patients were admitted to the Orthopedic and Trauma Surgery ward for hip fracture. Patients were randomly divided into two subgroups: (1) case (group C), had to receive patient-centered counseling throughout the hospitalization; and (2) control (group $\mathrm{NC}$ ), receiving the analgesic treatment without receiving counseling. Short Form-36-item Health Survey Questionnaire, State-Trait Anxiety Inventory, and Hamilton Rating Scale for Depression scores were recorded before any treatment, at discharge, and after 30 days. Pain levels were evaluated by means of Visual Analog Scale every 12 hours during the hospitalization from the day of surgery until day 5 .

Results: The hierarchical clustering analysis identified before any treatment were two clusters based on different physical functioning perceptions and role limitations, which were due to physical and emotional problems. Counseling did have a positive impact on quality of life on all patients, but in a more relevant way if patients were low functioning upon admittance to the ward. Anxiety and depression decreased in patients undergoing counseling, and their pain levels were lower than among patients not receiving it.

Conclusion: This study reveals that hip fracture patients can be clustered on the basis of Short Form-36 baseline scores. Counseling affects the evolution of mental and physical status in these patients, and the major benefit is reported in patients whose quality of life perception is worse after the trauma. Decreasing anxiety and depression levels, as well as more satisfying pain management, assessed by means of specific tests, confirm the effectiveness of counseling in elderly patients with hip fracture.

Keywords: counseling, cluster analysis, hip fracture, quality of life

\section{Introduction}

Hip fracture is common in the elderly and is associated with significant morbidity, mortality, and disability. ${ }^{1,2}$ Since about $50 \%$ of patients with a good functional status before a hip fracture are unable to regain their independent lifestyle, prevention of functional disability in such patients is one of the main targets for clinicians. ${ }^{3,4}$ The social and economic costs are a burden for patients and their families: in 2002, more than 86,000 hip fractures were recorded in Italy, mainly among individuals over 65 years of age $(93 \%)$, 
$73 \%$ of whom were women; ${ }^{5}$ furthermore, mortality associated with hip fractures is estimated to be around $20 \%-30 \%$ within the first year. ${ }^{6-8}$ In literature, high rates of depressive symptoms are reported after a hip fracture; these symptoms are associated with low motivation and have a high impact on functional recovery, ${ }^{9-12}$ so adequate pain management is a main concern among patients with hip fractures in order to avoid mental and physical complications and to allow proper compliance in rehabilitation. Moreover, in elderly patients, perioperative management is typically more complicated since it requires careful evaluation before surgery and extensive rehabilitation before discharge. ${ }^{13}$ In addition, the presence of anxiety, depression, and high levels of pain are known as important outcome predictors after hip fractures. ${ }^{14}$

Quality of life (QoL) is commonly defined as a person's sense of well-being within the areas of life that are personally evaluated as important; ${ }^{15,16}$ this is critical for survival and recovery among the hospitalized elderly population. Previous studies revealed that the perception of QoL among traumatologic patients after total hip replacement, as assessed by the Short Form 36-item Health Survey Questionnaire (SF-36), is significantly worse than in patients with osteoarthritis, and that emotional problems caused these major limitations. ${ }^{17}$ Until now, we have not identified studies evaluating strategies to modify the psychological status and consequent QoL of elderly patients who are considered to be at high risk of mortality and disability, except for some studies that were based on motivational videotapes ${ }^{18}$ and geriatric consultation. ${ }^{19}$

Supportive psychotherapy generally refers to the use of a supportive-expressive model in which a therapist provides emotional support, encourages the expression of feelings, and helps the client to develop positive coping skills. Clientcentered therapy developed by Carl R Rogers is a form of supportive psychotherapy based on empathy, respect for the individual, and total acceptance. The role of the counselor is to assume the client's internal frame of reference in order to let the client accept himself or herself, and discover his/ her strength and potentiality; as a consequence, the therapeutic relationship leads the client to new insights and to behavior changes in the direction of improved psychological adjustment. ${ }^{20}$

This study was launched with the primary endpoint of assessing if and to what extent the changes in one's perception of self, attitude toward self, as well as manner of perception and valuing process obtained during the interviews conducted by the counselor, affect anxiety, depression, and pain levels, and subsequently increase the QoL of elderly patients admitted to the Orthopedic and Trauma Surgery ward for hip fracture.

\section{Materials and methods}

The study protocol was approved by the Foggia "Riuniti" Hospital Ethics Committee, and written informed consent was obtained from all subjects. Patients admitted to the Orthopedic and Trauma Surgery ward of the "Ospedali Riuniti" in Foggia for hip fracture from May 2010 to September 2011 were considered for possible inclusion. According to the hospital's standards of care, every patient undergoes a thorough medical examination; on this occasion, verbal information regarding the medical and counseling procedures was provided by both a staff anesthesiologist and counselor (MG), and preliminary consent was obtained from every patient willing to receive counseling in addition to surgical and medical treatments. At the end of the colloquium, a written leaflet was provided to every patient. At their first visit to the Orthopedic and Trauma Surgery ward, all patients were approached by a resident anesthesiologist and the counselor; patients' compliance with the inclusion and exclusion criteria was checked, and written informed consent was obtained. Inclusion criteria were age $>70$ years, presence of a hip fracture scheduled for surgical treatment, American Society of Anesthesiologists ratings of operative risk of 1-2-3, and a Mini-Mental State Evaluation (MMSE) score $\geq 11$. Exclusion criteria were age $<70$ years, inability or unwillingness to give informed consent, MMSE score $<11$, an American Society of Anesthesiologist rating of 4-5, postoperative use of ventilatory support or mechanical ventilation, or admittance to an intensive care unit.

\section{Study protocol}

At the first visit, the patients were randomly divided into two subgroups using a computer-generated table: (1) the counseling group (C), had to receive patient-centered counseling throughout the hospitalization; and (2) the control group (NC) received the analgesic treatment without counseling. Clinicians in charge of the patients were unaware of the patients' allocation.

\section{Counseling}

Since the first meeting and during the whole period of medical treatment, patients allocated into the treatment subgroups received the client-centered therapy developed by Carl R Rogers. ${ }^{20-22}$ This model helps patients gain awareness and be responsible for themselves in order to work out their difficulties. 
Counseling was performed by a trainee counselor (MG), who met the patients twice a week almost at the same time each week for about 45 minutes, and had who no interference with the medical treatment established by the clinicians in the ward; baseline measurements including scores on the MMSE, SF-36, Hamilton Rating Scale for Depression (HAM-D), and State-Trait Anxiety Inventory Y1 (STAIY1) were performed.

\section{Tests and questionnaires}

The MMSE is commonly used to assess an individual's cognitive mental status; it can be administered in less than 10 minutes by following its simple instructions, ${ }^{23,24}$ and even though it cannot be used for a formal diagnosis, it is often used as the first step in detecting cognitive impairment. ${ }^{25,26}$ The cut-off score of 11 was chosen because severe cognitive impairment could be an obstacle for successful counseling sessions.

Psychodiagnostic and QoL tests were recorded before any treatment $\left(\mathrm{T}_{0}\right)$, upon discharge from the ward $\left(\mathrm{T}_{1}\right)$, and after 30 days $\left(T_{2}\right)$ through a telephone interview.

We used the Italian version of the SF-36, translated according to a strictly defined protocol validated for use in Italy. ${ }^{27}$ The items of the SF-36 are grouped into eight subscales: physical functioning (PF; ten items), role limitation due to physical problems (RP; four items), role limitation due to emotional problems (RE; three items), bodily pain (BP; two items), social functioning (SF, two items), mental health (MH; five items), vitality (VT; four items), and general health perception (GH; five items). Five items (PF, RP, BP, GH, and VT) are related to physical status; the remaining three (social functioning, RE, MH) are related to mental status. The response choices for the role-functioning scales (physical and emotional) are dichotomous (yes/no); the other items have three to six response choices. To calculate every item score, the raw scores were coded and recalibrated following the standard guidelines, and the items were then summed and transformed to the eight scales with scores ranging from $0-100(0=$ worst health; $100=$ best health $) .{ }^{28}$

The presence and severity of symptoms of anxiety in participants were determined using the Spielberg State-Trait Anxiety Inventory. This self-report questionnaire consists of 20 items for the evaluation of state anxiety (STAI-Y1) and 20 items for the evaluation of trait anxiety (STAI-Y2). We decided to perform only the STAI-Y1, since it is a measure of the anxiety experienced at the time of the test, and the goals were to assess the current levels of anxiety due to the trauma, hospitalization, and surgery, as well as to evaluate the influence of counseling on patients. Each item score ranges from one to four, and the scores were summed to calculate the total score. Scores from 20 to 31 are indicative of mild anxiety; scores from 32 to 53 reflect a moderate level of anxiety; and scores higher than 54 are labeled as severe. ${ }^{29}$

To assess the presence and severity of depression, we used the HAM-D. This test explores all symptoms of depression including paranoid ideation, depersonalization, derealization, and obsessions, and it also evaluates somatic symptoms. It is a 21 -item scale, and each item is rated from 0 to 4 , except for two items rated from 0 to 2 . The total score ranges from 0 to 84 . The HAM-D has good validation, is easy to administer, and is widely used in studies on depression. A HAM-D score $\geq 10$ is related to clinically significant depressive symptoms. ${ }^{30,31}$

\section{Anesthesia management}

On arrival in the surgery room, intravenous premedication was given by means of midazolam $(0.03-0.04 \mathrm{mg} / \mathrm{kg})$, fentanyl (50 mcg), ranitidin (50 mg), and ondansetron (4 mg). Therefore, injection of $10 \mathrm{mg}(0.5 \%)$ of isobaric levobupivacaine and $20 \mathrm{mcg}$ of fentanyl into the subarachnoid space (spinal anesthesia) for surgery was provided. Standardized fluid and transfusion therapy were given during the entire perioperative phase. All procedures were performed by the same senior anesthesiologist (AD) and surgeon (AM), who were unaware of patients' allocation. With regards to the management of postoperative pain, a standard protocol was applied: all the patients had a nurse-controlled analgesia pump with intravenous ketorolac $(120 \mathrm{mg})$, ranitidin (300 mg), and ondansetron ( $8 \mathrm{mg}$ ) $2 \mathrm{~mL} /$ hour until the second postoperative day. All patients received additional analgesia with acetaminophen $1 \mathrm{~g}$ every 8 hours.

After the operation, the patients were mobilized, if possible, on the day of surgery, and a physiotherapy program started on the first postoperative day (day 1).

Patients were primarily rehabilitated in the orthopedic ward and were then discharged to their home or to a rehabilitation facility.

\section{Pain assessment}

Evaluation of postoperative pain was performed by means of the Visual Analog Scale (VAS) for a total of eleven evaluations, from the day of surgery beginning at $8 \mathrm{pm}$, until day 5 , every 12 hours. VAS is the most commonly used measure of pain in clinical settings. ${ }^{32}$ Results are to be considered as follows: mild/no pain, 0-30; moderate pain, 31-69; and severe pain, $70-100 . .^{33}$ 


\section{Statistics and data analyses}

Data are given as mean values \pm standard deviations, or $95 \%$ confidence intervals, as appropriate.

The sample size was calculated assuming that changes of 5-10 points in the SF-36 subscales were considered to reflect the minimum clinically important difference. ${ }^{34}$ On the basis of this data, a sample size of 20 individuals in each group was calculated as being sufficient to detect a difference of nine points on the SF-36 subscales, assuming a standard deviation of ten points, a power of $80 \%$, and a significance level of $5 \%$.

Demographics between the groups were compared with $\chi^{2}$, or Fisher's exact test for categorical data; nonpaired, two-tailed Student's $t$-test for continuous data; and the Mann-Whitney $U$ test for nonparametric data.

SF-36 data analysis was performed by means of cluster analysis, an agglomerative hierarchical method that divides data into groups of similarities (clusters) that are meaningful, useful, or both. ${ }^{35}$ We performed cluster analysis by means of Ward's method, which uses an analysis of variance (ANOVA) approach to evaluate the distances between clusters. First, a joining analysis (tree/hierarchical clustering) was performed to evaluate how many of the "natural" clusters that could be labeled in a meaningful manner were formed by the patients in each group; afterwards, the $k$-mean clustering method was applied based on this number of clusters in order to assign observations to each cluster. Cluster analysis was conducted using the eight SF-36 items recorded at $\mathrm{T}_{0}$. One-way ANOVAs were then used to examine whether clusters were significantly different in terms of demographic variables and other psychometric test values at baseline. The next step was to use repeated measures ANOVAs to explore the possible effect of counseling on each patient's well-being and psychological status, measured by SF-36, STAI-Y1, HAM-D, and pain levels assessed by VAS over time. If significant, Fisher's exact test was applied for post hoc comparisons between the different experimental conditions. $P<0.05$ was the minimal value accepted as statistically significant. All calculations were performed using the software package Statistica 8 (StatSoft, Inc, Tulsa, OK, USA).

\section{Results}

\section{Patient sample}

A total of 40 patients of the 68 initially evaluated for enrolment were included in the study. Figure 1 shows a flow diagram of patient inclusion.

Table 1 shows the demographic characteristics and the SF-36, STAI-Y1, and HAM-D baseline scores of the population studied. Overall, patients in the $\mathrm{C}$ and $\mathrm{NC}$ groups were

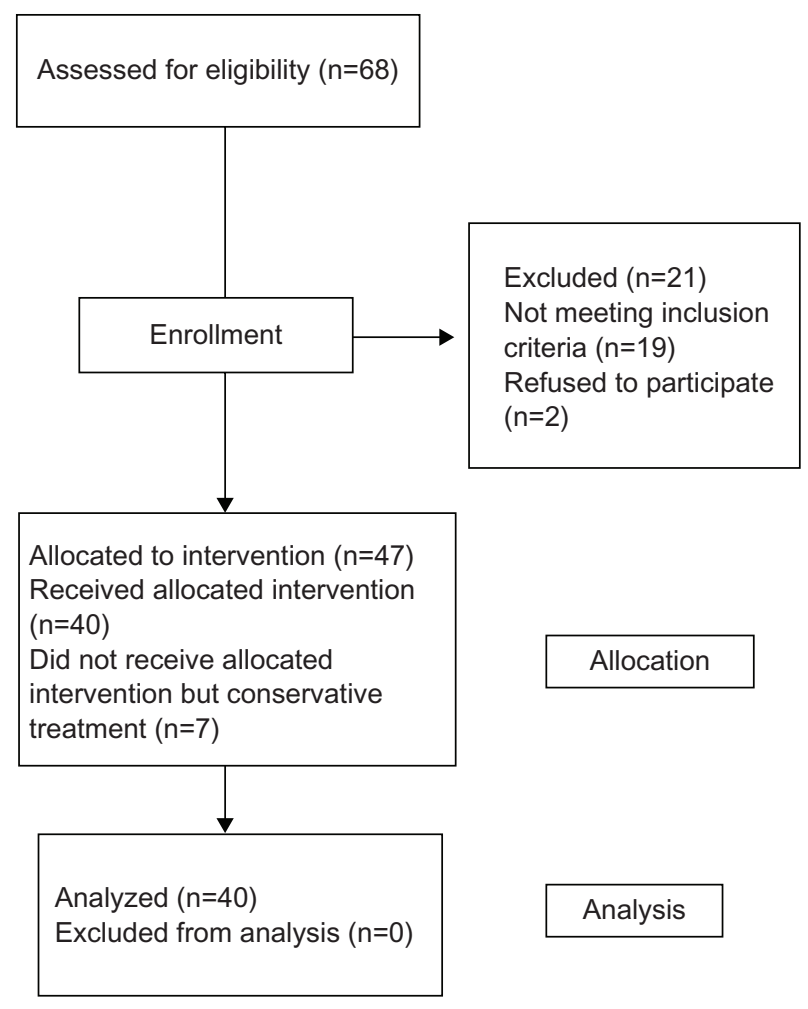

Figure I Flow diagram of the progress through the phases of the trial. Abbreviation: $\mathrm{n}$, number.

comparable in terms of demographics, and no differences were reported between the groups at $\mathrm{T}_{0}$.

\section{Health-related quality of life}

Table 2 shows the scores for the SF-36, STAI-Y1, and HAM-D for the two groups. With regards to the QoL perception, in group $\mathrm{C}$ we found increased scores for VT, PF, RP, $\mathrm{RE}$, and $\mathrm{MH}\left(\mathrm{T}_{2}\right.$ versus $\left.\mathrm{T}_{0} ; P<0.05\right)$; in group $\mathrm{NC}$, all the items remained unmodified, except for $\mathrm{PF}$, which decreased at $\mathrm{T}_{2}(P<0.05)$.

At $\mathrm{T}_{0}$, hierarchical clustering analysis identified two clusters based on different PF perceptions (RP and RE), while clusters were not identified for the other items (Figure 2). A total of 16 patients had a PF score of $72.5 \pm 5$, an RP score of $80.3 \pm 8.5$, and an RE score of $70.3 \pm 9.6$ (cluster 1); 24 patients had a PF score of $33.4 \pm 6$, an RP score of 0 , and an RE score of $7.6 \pm 3.7$ (cluster 2). The $k$-mean cluster analysis identified members of each cluster for the subsequent ANOVA analysis, which confirmed a significant difference in the mean PF, RP, and RE score between the clusters, and identified specific characteristics among clusters. Table 3 shows the demographic characteristics and the baseline scores for SF-36 in the two clusters. No demographic characteristic differences were found between 
Table I Demographic characteristics and baseline tests of the population studied

\begin{tabular}{|c|c|c|c|}
\hline & $\begin{array}{l}\text { Group C } \\
(n=20)\end{array}$ & $\begin{array}{l}\text { Group NC } \\
(n=20)\end{array}$ & ANOVA \\
\hline Age (years) & $81.3 \pm 7$ & $80.3 \pm 6$ & NS \\
\hline Male/female ratio & $1 / 19$ & $2 / 18$ & NS \\
\hline Marital status (n) & & & NS \\
\hline Married & 6 & 7 & \\
\hline Widowed & 14 & 13 & \\
\hline Educational level (n) & & & NS \\
\hline Primary school or less & 15 & 16 & \\
\hline Secondary school & 5 & 4 & \\
\hline Type of fracture (n) & & & NS \\
\hline Intracapsular fractures & 7 & 5 & \\
\hline $\begin{array}{l}\text { Trochanteric and } \\
\text { basocervical fractures }\end{array}$ & 13 & 15 & \\
\hline Hospitalization (days) & & & NS \\
\hline Total & $14.9 \pm 4.5$ & $15 \pm 5.2$ & \\
\hline Preoperative & $8.3 \pm 3.3$ & $8.4 \pm 3.4$ & \\
\hline Postoperative & $6.5 \pm 2.9$ & $6.7 \pm 4$ & \\
\hline SF-36 items (mean \pm SD) & & & NS \\
\hline General health & $88.7 \pm 2.7$ & $95 \pm 1.1$ & \\
\hline Vitality & $56.5 \pm 2$ & $52 \pm 3.4$ & \\
\hline Bodily pain & $59.2 \pm 3$ & $61.8 \pm 5.5$ & \\
\hline Physical functioning & $53.5 \pm 5.5$ & $45.8 \pm 9$ & \\
\hline Role limitation, physical & $34.2 \pm 9.9$ & $33.3 \pm 11.4$ & \\
\hline Role limitation, emotional & $32.9 \pm 8.3$ & $35.2 \pm 11.2$ & \\
\hline Social functioning & $62.4 \pm 4.4$ & $58.6 \pm 3.9$ & \\
\hline Mental health & $50.9 \pm 2$ & $55.7 \pm 4.2$ & \\
\hline STAI-YI $($ mean \pm SD $)$ & $54.1 \pm 13.1$ & $49 \pm 12.9$ & NS \\
\hline HAM-D (mean \pm SD) & $15.7 \pm 9.3$ & $11.2 \pm 5.6$ & NS \\
\hline
\end{tabular}

Abbreviations: $\mathrm{C}$, with counseling; $\mathrm{n}$, number; $\mathrm{NC}$, with analgesia alone and without counseling; ANOVA, analysis of variance; NS, no significant difference; SF-36, Short Form 36-item health survey questionnaire; SD, standard deviation; STAI-YI, StateTrait Anxiety Inventory; HAM-D, Hamilton Rating Scale for Depression.

patients entering each cluster, but the hospitalization length among cluster 1 patients was longer than that among cluster 2 patients $(P<0.05)$, specifically for the postoperative stay $(P<0.05)$. SF-36 mean values at $\mathrm{T}_{0}$ are presented in Figure 3 and in Table 3. Patients entering cluster 1 had a better overall status with very low RP or RE scores. Patients entering cluster 2 had a worse overall status: the low PF score was associated with high RP and RE scores when compared to cluster $1(P<0.001)$. No difference between clusters was found regarding the remaining SF-36 items.

In Figures 4 and 5, SF-36 intra- and intergroup comparisons between patients undergoing and not undergoing counseling (group $\mathrm{C}$ versus group $\mathrm{NC}$ ) are illustrated.

After surgical intervention and rehabilitation, the PF score registered at $\mathrm{T}_{2}$ improved in all patients, independent from cluster allocation and counseling $(P<0.05)$.

In cluster 1 from $\mathrm{T}_{0}$ to $\mathrm{T}_{2}$, VT improved in all patients $\left(P<0.05\right.$ in group $\mathrm{C}, \mathrm{T}_{2}$ versus $\mathrm{T}_{0} ; P<0.01$ in group $\mathrm{NC}$,
Table 2 Time course of the tests in group $C$ and in the NC group

\begin{tabular}{|c|c|c|c|}
\hline & $\begin{array}{l}\text { Group C } \\
\text { at } T_{0}\end{array}$ & $\begin{array}{l}\text { Group C } \\
\text { at } T_{2}\end{array}$ & ANOVA \\
\hline \multicolumn{4}{|l|}{ SF-36 items (mean \pm SD) } \\
\hline General health & $88.7 \pm 2.7$ & $89.4 \pm 1.8$ & NS \\
\hline Vitality & $56.5 \pm 2$ & $67.2 \pm 3.3$ & $P<0.05$ \\
\hline Bodily pain & $59.2 \pm 3$ & $51.3 \pm 4.4$ & NS \\
\hline Physical functioning & $53.5 \pm 5.5$ & $75.3 \pm 5.7$ & $P<0.05$ \\
\hline Role limitation, physical & $34.2 \pm 9.9$ & $66.9 \pm 8.1$ & $P<0.05$ \\
\hline Role limitation, emotional & $32.9 \pm 8.3$ & $63.4 \pm 8$ & $P<0.05$ \\
\hline Social functioning & $62.4 \pm 4.4$ & $61.1 \pm 3.7$ & NS \\
\hline Mental health & $50.9 \pm 2$ & $68.4 \pm 1.7$ & $P<0.05$ \\
\hline STAI-YI (mean \pm SD) & $54.1 \pm 13.1$ & $45 \pm 11.2$ & $P<0.05$ \\
\hline \multirow[t]{2}{*}{ HAM-D (mean $\pm S D)$} & $15.7 \pm 9.3$ & $5.7 \pm 4.2$ & $P<0.0 \mathrm{I}$ \\
\hline & $\begin{array}{l}\text { Group NC } \\
\text { at } T_{0}\end{array}$ & $\begin{array}{l}\text { Group NC } \\
\text { at } \mathrm{T}_{2}\end{array}$ & \\
\hline \multicolumn{4}{|l|}{ SF-36 items (mean \pm SD) } \\
\hline General health & $95 \pm 1.1$ & $86.6 \pm 3.8$ & NS \\
\hline Vitality & $52 \pm 3.4$ & $54.7 \pm 3.2$ & NS \\
\hline Bodily pain & $61.8 \pm 5.5$ & $53.2 \pm 4.3$ & NS \\
\hline Physical functioning & $45.8 \pm 9$ & $70.3 \pm 6.6$ & $P<0.05$ \\
\hline Role limitation, physical & $33.3 \pm 11.4$ & $46.9 \pm 12.3$ & NS \\
\hline Role limitation, emotional & $35.2 \pm 11.2$ & $44.2 \pm 11.3$ & NS \\
\hline Social functioning & $58.6 \pm 3.9$ & $56.2 \pm 2.7$ & NS \\
\hline Mental health & $55.7 \pm 4.2$ & $56.7 \pm 3.8$ & NS \\
\hline STAI-YI (mean \pm SD) & $49 \pm 12.9$ & $49 \pm 13.1$ & NS \\
\hline HAM-D (mean \pm SD) & $11.2 \pm 5.6$ & $10.9 \pm 9.2$ & NS \\
\hline
\end{tabular}

Abbreviations: $C$, counseling; NC, with analgesic alone and without counseling; $\mathrm{T}_{0}$, baseline; $\mathrm{T}_{2}$, after 30 days; ANOVA, analysis of variance; SF-36, Short Form 36-item Health Survey Questionnaire; SD, standard deviation; NS, no significant difference; STAI-YI, State-Trait Anxiety Inventory; HAM-D, Hamilton Rating Scale for Depression.

$T_{2}$ versus $T_{0}$ ) without differences between the groups, while there was a significant difference with respect to $\mathrm{GH}$ (in the $\mathrm{NC}$ group, it decreased at $\mathrm{T}_{2}\left[P<0.05\right.$ versus $\left.\mathrm{T}_{0}\right]$ and remained unchanged in the $\mathrm{C}$ group). The remaining items remained unmodified (Figure 4).

In cluster 2 from $\mathrm{T}_{0}$ to $\mathrm{T}_{2}, \mathrm{RP}$ and RE scores improved only in patients undergoing counseling $(P<0.001$ versus $\left.\mathrm{T}_{0}\right)$, while in $\mathrm{NC}$ patients, the scores of the two items remained very low, indicating that the role limitation due to both physical and emotional problems, noticed at the baseline evaluation, did not change in this group of patients. In all cluster 2 patients, an increased impact of BP was found $(P<0.05)$. With regards to the remaining items, no change was reported among patients who underwent counseling and those who did not (Figure 5).

\section{Psychological status}

Figure 6 shows HAM-D and STAI-Y1 data for both groups. Defining depression as HAM-D $\geq 10$, all patients were considered to be depressed at admission to the hospital 
Tree diagram for 40 cases
hip fracture

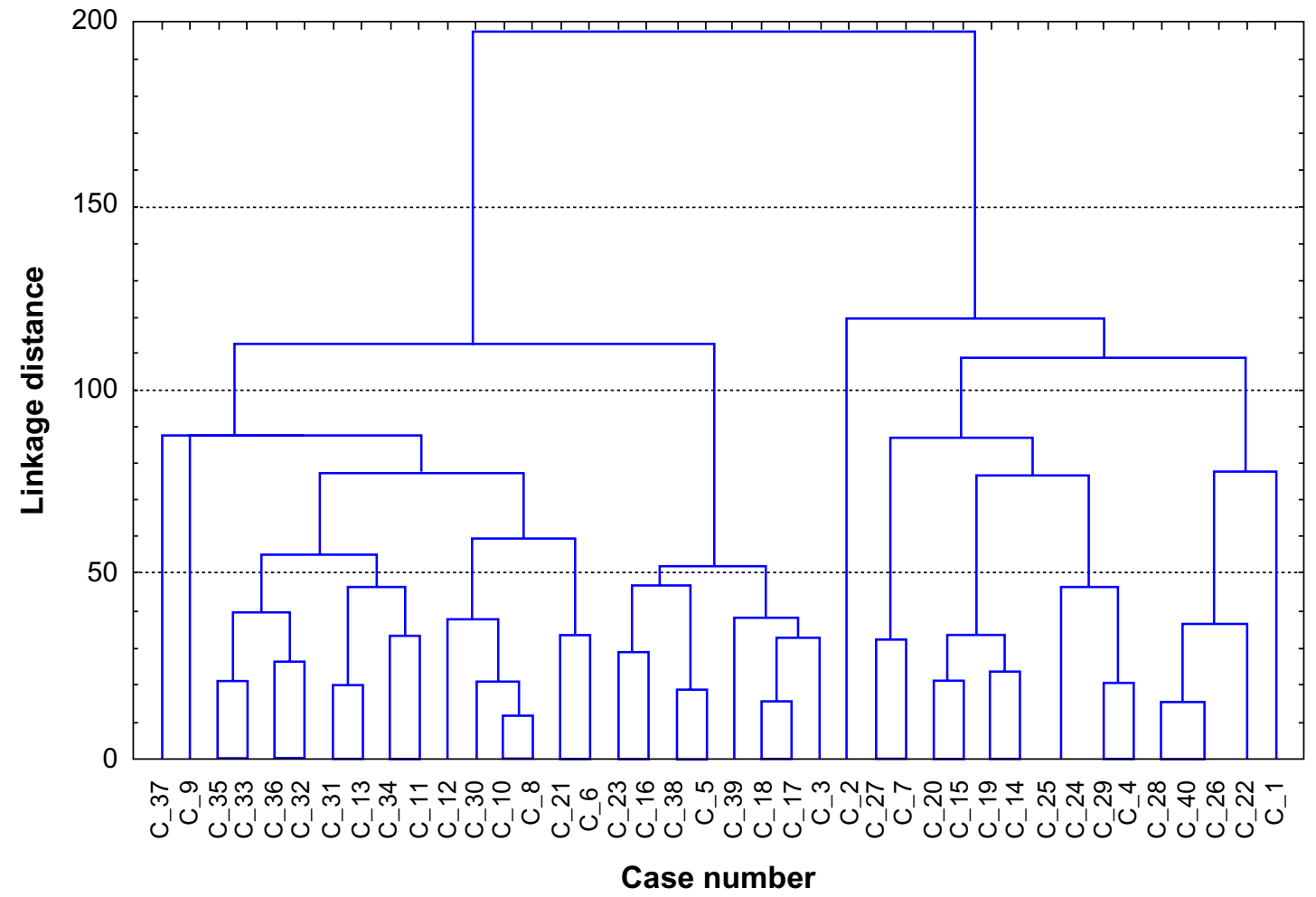

Figure 2 Dendrograms for hierarchical agglomerate clustering of patients.

Notes: The $\mathrm{X}$-axis represents the cases; each row on the $\mathrm{Y}$-axis represents one patient. Because of the limited resolution of the dendrogram, cases were not labeled. The $Y$-axis represents the distance of linkage between the patient clusters. Highly correlated clusters are closer to the bottom side of the dendrogram, while less correlated clusters are more distant from the $\mathrm{X}$-axis. As they move up the dendrogram, clusters get bigger; each horizontal line represents a merge. The $\mathrm{Y}$-coordinate of the horizontal line is the similarity of the clusters that were merged.

$(15.7 \pm 9.3$ in group $\mathrm{C}$ and $11.2 \pm 5.6$ in group $\mathrm{NC}$ Table 2). Patients undergoing counseling showed decreasing HAM-D scores at $\mathrm{T}_{2}$ when compared to the baseline evaluation $(P<0.01)$, and they could be defined as being nondepressed (HAM-D $\leq 10)$. Depression levels in patients not undergoing counseling remained stable throughout the observation period.

Patients showed moderate-to-severe baseline anxiety levels, but there was no significant difference between groups (the mean STAI-Y1 score was $54.1 \pm 13.1$ in group $\mathrm{C}$ and $49 \pm 12.9$ in group NC; Table 2). In patients undergoing counseling (group C ) STAI-Y1 scores at $\mathrm{T}_{2}$ were lower than at admission $(P<0.05)$, while the reduction of anxiety levels was not reported in group NC.

\section{Postoperative pain assessment}

Pain scores are presented in Figure 7. Pain levels were moderate at the first evaluation (the day of surgery, at $8 \mathrm{pm}$ ) in both groups of patients (VAS: $36 \pm 6$ in group C; $35 \pm 7$ in group $\mathrm{NC}$; no difference). In patients receiving counseling (group C), pain levels showed a progressive decrease, with VAS scores below 30 at day 1, and approximately no pain at all was found at days 4 and 5 postoperatively. Patients not undergoing counseling reported greater pain levels throughout the postoperative period when compared with group C, with VAS scores significantly higher in day 4 at 8 pm and day 5 at 8 am $(P<0.01)$. Sharper pain in group NC resulted in increased discomfort, sleep troubles, and painkiller requests.

\section{Discussion}

The main results of the present study are that:

1. PF, RE, and RP are the discriminating parameters among elderly patients with hip fracture upon admission to the Orthopedic and Trauma Surgery ward. In fact, cluster analysis identified two clusters, or types, of patients with different perceptions of self-PF and role perception due to physical and emotional problems, as characterized by low and high baseline levels for PF, RE, and RP, respectively. Lower scores in PF, RE, and RP indicate an important limitation in performing work and other daily activities as 
Table 3 Demographic characteristics and baseline tests of clusters

\begin{tabular}{|c|c|c|c|}
\hline & $\begin{array}{l}\text { Cluster I } \\
(n=16)\end{array}$ & $\begin{array}{l}\text { Cluster } 2 \\
(n=24)\end{array}$ & ANOVA \\
\hline Age (years) & $80.9 \pm 5$ & $81 \pm 8$ & NS \\
\hline Male/female ratio & $1 / 15$ & $2 / 22$ & NS \\
\hline Marital status (n) & & & NS \\
\hline Married & 5 & 8 & \\
\hline Widowed & II & 16 & \\
\hline Educational level (n) & & & NS \\
\hline Primary school or less & 13 & 18 & \\
\hline Secondary school & 3 & 6 & \\
\hline Type of fracture (n) & & & NS \\
\hline Intracapsular fractures & 5 & 7 & \\
\hline $\begin{array}{l}\text { Trochanteric and } \\
\text { basocervical fractures }\end{array}$ & II & 17 & \\
\hline \multicolumn{4}{|l|}{ Hospitalization (days) } \\
\hline Total & $16.8 \pm 5.9$ & $13.6 \pm 3.4$ & $P<0.05$ \\
\hline Preoperative & $8.9 \pm 3.8$ & $8 \pm 2.9$ & NS \\
\hline Postoperative & $7.9 \pm 4.3$ & $5.6 \pm 2.1$ & $P<0.05$ \\
\hline \multicolumn{4}{|l|}{ SF-36 items $($ mean $\pm S D)$} \\
\hline General health & $90 \pm 2.6$ & $92.9 \pm 2$ & NS \\
\hline Vitality & $56.3 \pm 2.6$ & $52.9 \pm 2.8$ & NS \\
\hline Bodily pain & $55.7 \pm 5.5$ & $63.8 \pm 3.2$ & NS \\
\hline Physical functioning & $72.5 \pm 5$ & $33.4 \pm 6$ & $P<0.001$ \\
\hline Role limitation, physical & $80.3 \pm 8.5$ & 0 & $P<0.001$ \\
\hline Role limitation, emotional & $70.3 \pm 9.6$ & $7.6 \pm 3.7$ & $P<0.001$ \\
\hline Social functioning & $54.9 \pm 5.5$ & $64.8 \pm 2.9$ & NS \\
\hline Mental health & $59.4 \pm 2.7$ & $48.6 \pm 3.1$ & NS \\
\hline
\end{tabular}

Abbreviations: $n$, number; ANOVA, analysis of variance; NS, no significant difference; SF-36, Short Form 36-item health survey questionnaire; SD, standard deviation. a result of physical health and emotional problems, while higher scores are related to one's ability to perform all types of physical activities, including those that are most vigorous, without limitations due to health. The group of patients who showed worse QoL upon admittance to the ward after hip fracture is characterized by a particularly bad reaction to the trauma and to hospitalization, with patients having very low role perception and poor confidence in their ability to regain good performance status; we defined these individuals as "low-functioning patients." Recently Dr James Eisenach stated that the central problem of pain illness may be the impact on functioning, so the efforts in treating the pain should be directed to increase function and enjoyment of life, regardless of changes in pain scores. ${ }^{36}$

2. PF improved in all patients during the observation period. This was an expected result, as it was a consequence of the success of the surgical procedure and the rehabilitation; it was associated with progressive improvement of in the patients' physical performances.

3. Attending counseling led to a significant difference in low-functioning patients; showing a relevant improvement in QoL perception, these patients obtained major benefit from the treatment. This improvement was lacking among patients not undergoing counseling.

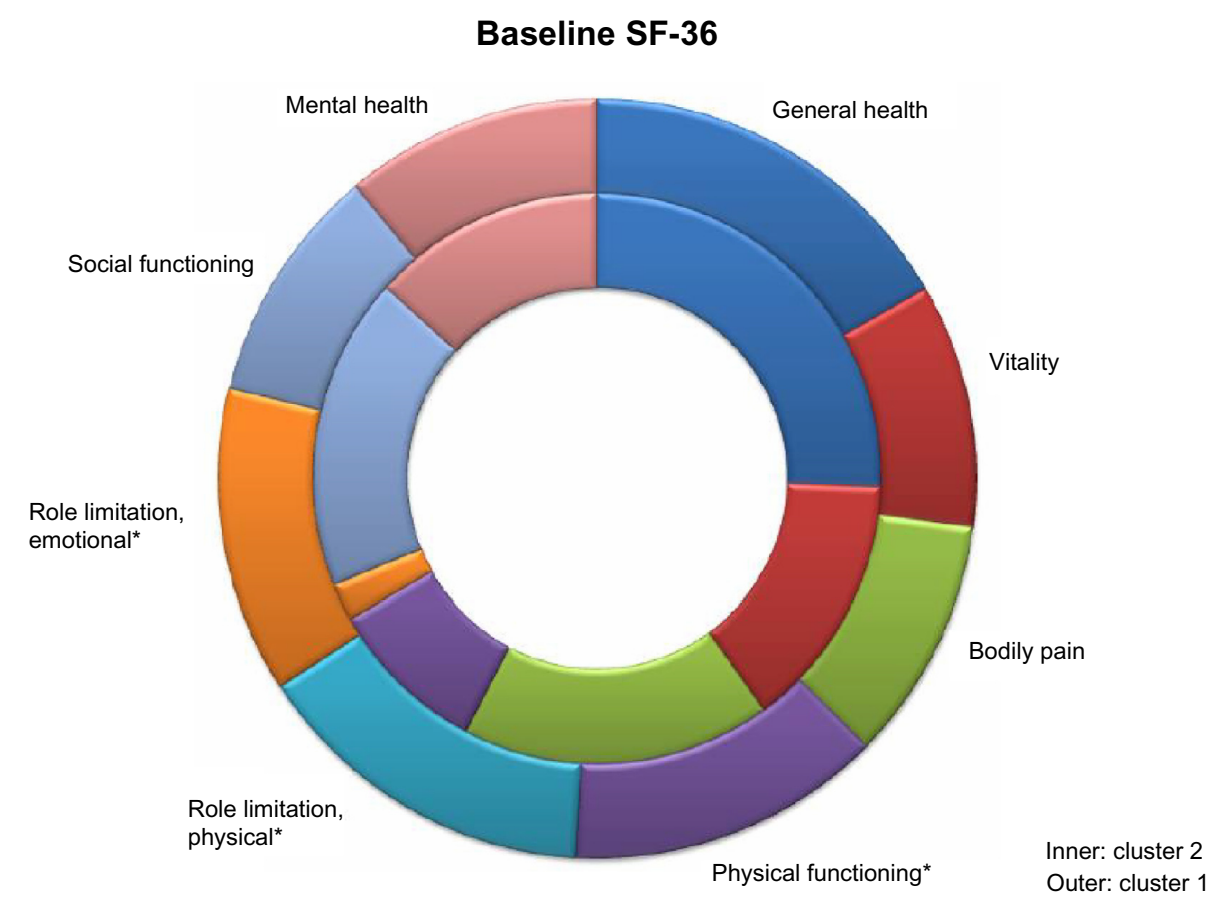

Figure 3 Baseline SF-36 in the different clusters.

Note: ${ }^{*} P<0.00$ I (cluster I versus cluster 2).

Abbreviation: SF-36, Short Form 36-item Health Survey Questionnaire. 


\section{Cluster 1}

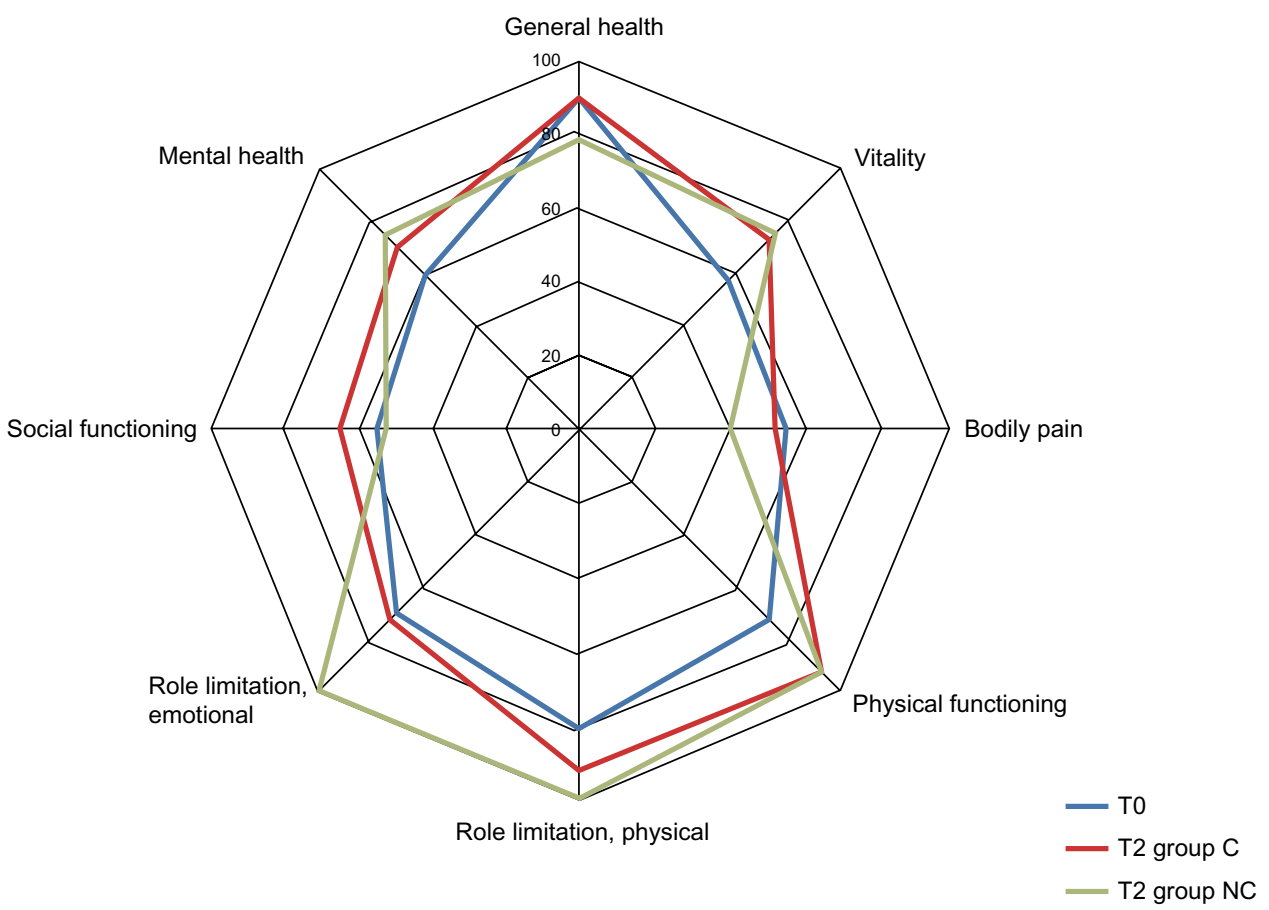

Figure 4 SF-36 time course in cluster I: T0 (whole group), T2 (group C), T2 (group NC).

Abbreviations: SF-36, Short Form 36-item Health Survey Questionnaire; T0, baseline; C, with counseling; T2, after 30 days; NC, with analgesia alone and without counseling.

\section{Cluster 2}

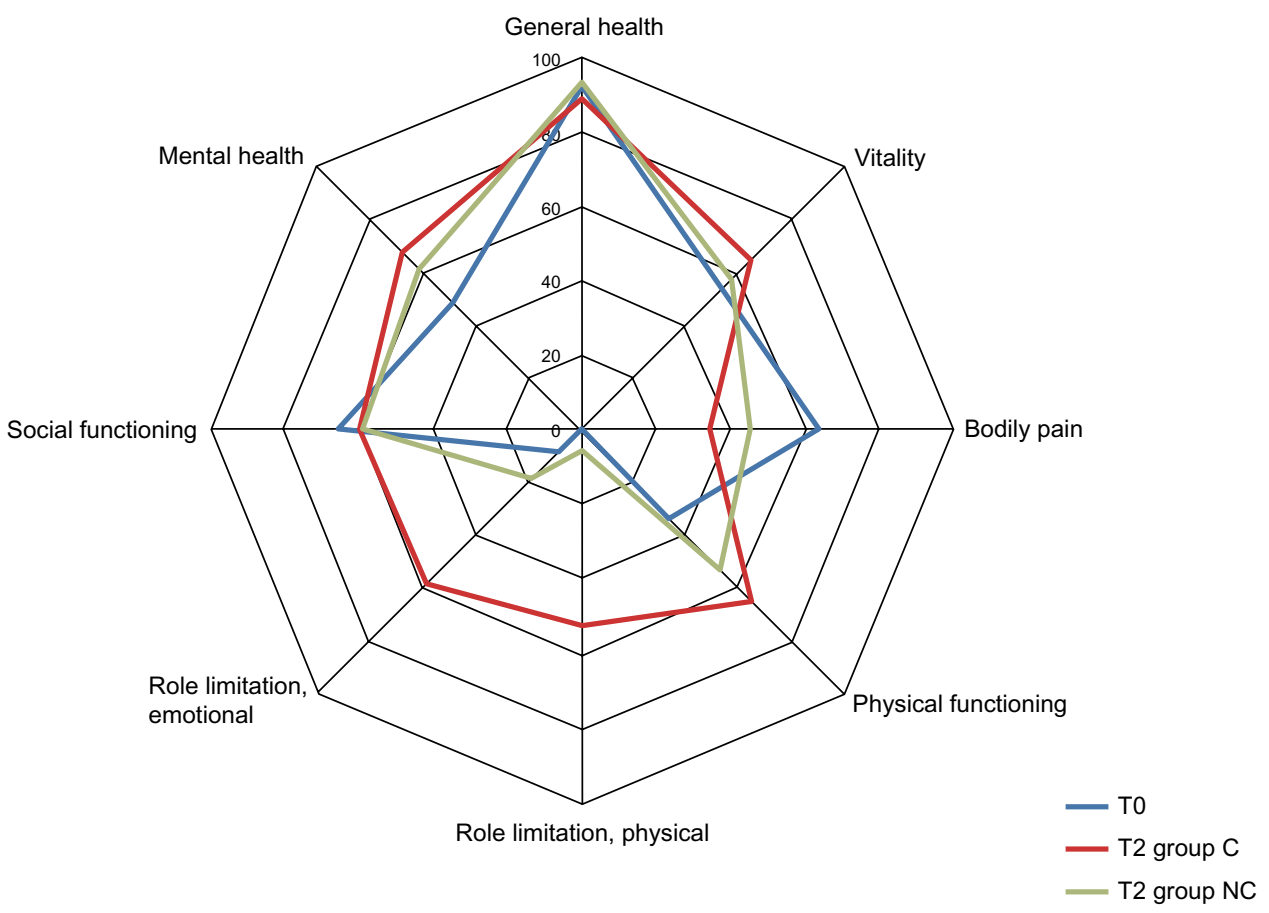

Figure 5 SF-36 time course in cluster 2: T0 (whole group), T2 (group C), T2 (group NC).

Abbreviations: SF-36, Short Form 36-item Health Survey Questionnaire; T0, baseline; C, with counseling; T2, after 30 days; NC, with analgesia alone and without counseling. 

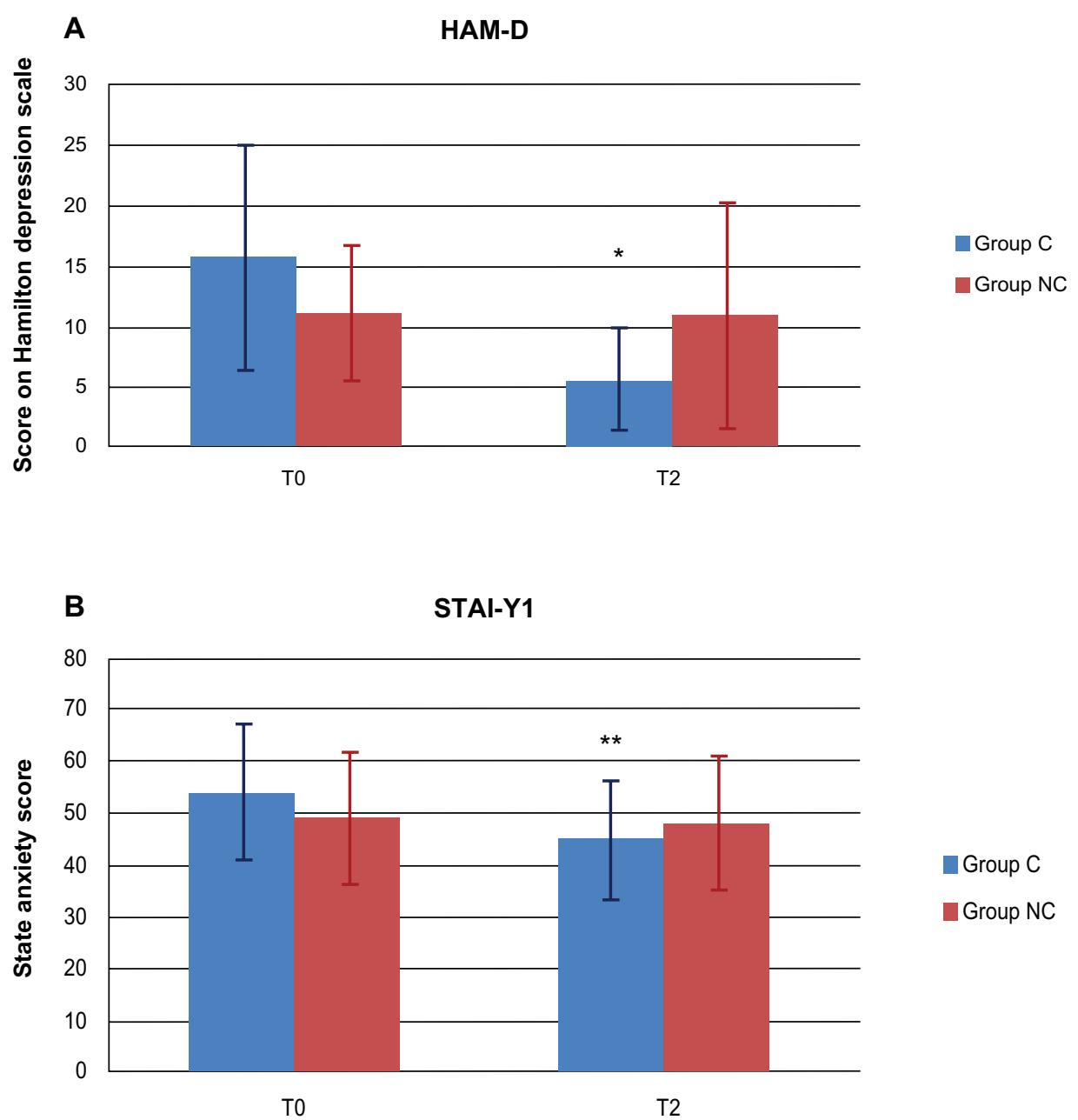

Figure 6 STAI-YI and HAM-D time course.

Notes: Time course of (A) STAI-YI and (B) HAM-D administration. $* P<0.01$; **P $<0.05$; T2 versus T0 (group C).

Abbreviations: STAI-YI, State-Trait Anxiety Inventory; T2, after 30 days; T2, baseline; C, counseling; NC, with analgesic alone and without counseling; HAM-D, Hamilton Rating Scale for Depression.

The effectiveness of counseling in our study is confirmed in our patients by the important results obtained with regards to anxiety and depression, and as explored by specific tests. Among patients not undergoing counseling, there was no reduction at all in STAI-Y1 and HAM-D scores, while the supportive psychotherapy led to an improvement in the patients' psychological status, which is reflected in greater levels of satisfaction and improved compliance during the rehabilitation program. The deep interrelation between pain perception and patients' psychological status has been recently studied in animal models by Bravo et a ${ }^{37}$ who demonstrated that depression leads to emotional dysfunction in the interpretation of pain.

In our opinion, these important results indicate the need to identify the types of patients that we defined as "low-functioning" early on, by means of administering the
SF-36, an instrument used worldwide to assess health-related QoL. This category of patients seems to show a strong need for support, and this group is able to benefit from counseling. The obvious implication is that the administration of the SF-36 in elderly patients upon admission to hospital after a hip fracture should be done on a regular basis; this would allow the clinicians to identify the types of patients whose need for psychological support is the strongest, in order to obtain the best possible results using an integrated approach that includes surgery, pain treatment, rehabilitation, and counseling.

Another critical result of the present study is that there was a significant difference in pain perception, assessed by means of VAS, among the two groups of patients; those attending counseling achieved better pain management, even if the protocol for postoperative pain management was the same in all patients. This indicates the importance of psy- 


\section{VAS}

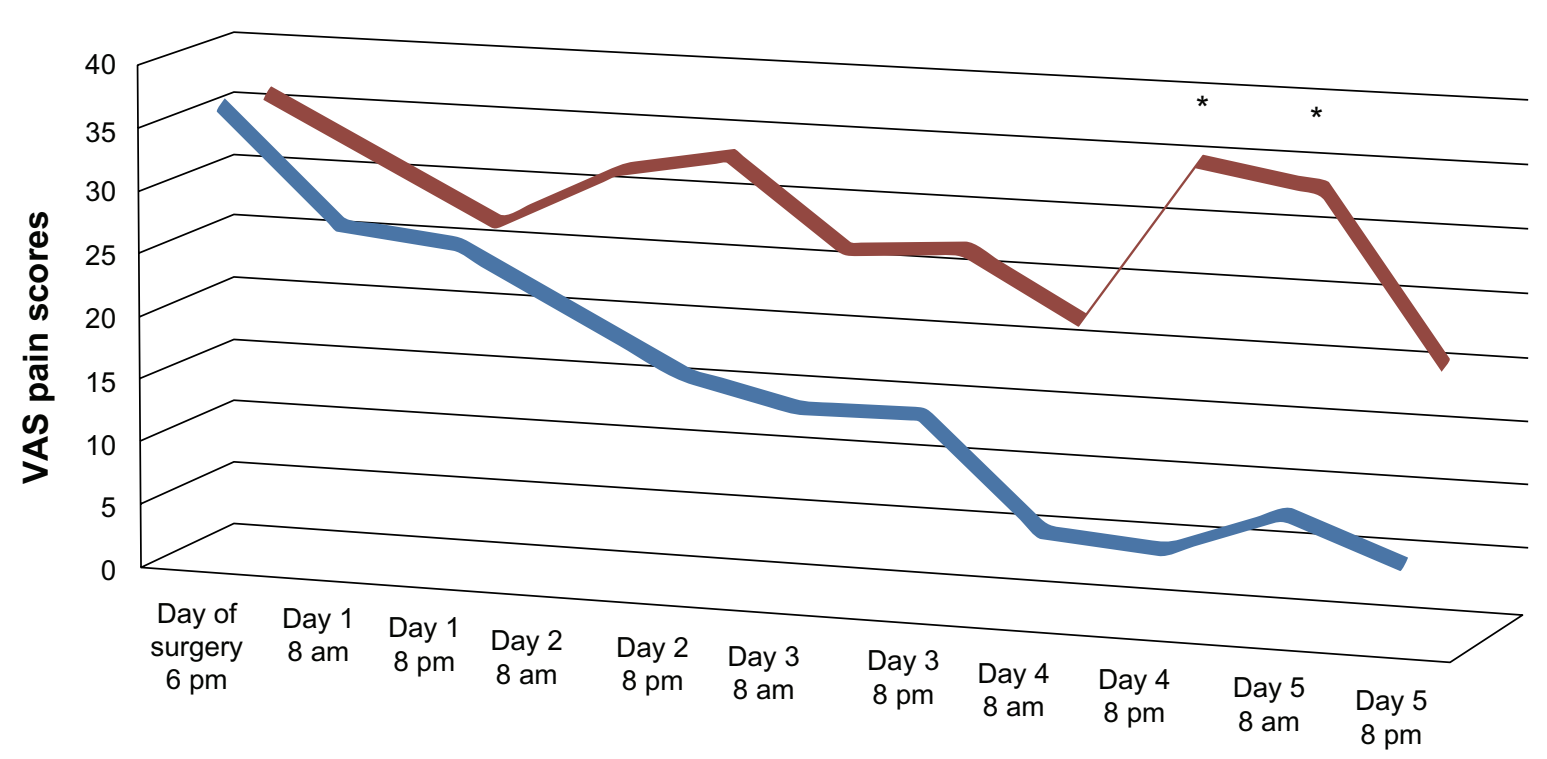

- Group C

- Group NC

Figure 7 VAS time course.

Note: $* P<0.01$ Group C versus Group NC.

Abbreviations: VAS, Visual Analog Scale; C, counseling; NC, with analgesic alone and without counseling.

chological support in addressing suffering, fear, and other psychological components of pain. Treatment of the physical component of pain alone may lead to incomplete success of therapy, while integrating counseling in the standard pain treatment allows the patient to properly react to the stressful condition and to regain confidence in his or her resources, which is essential to finding the motivation required throughout the rehabilitation program after surgery.

The novelty of the present study, in our opinion, is the application of counseling to influence a patient's psychosocial conditions and self-perceptions throughout the perioperative period, in order to challenge anxiety and depression to subsequently improve pain management and to obtain a better QoL.

Psychosocial factors increase pain severity, and emotional distress (particularly anxiety, depression, and beliefs about pain) has emerged as being predictive of pain levels. ${ }^{38}$ As a consequence, it is important to not only assess the intensity and frequency of physical pain, but to also examine the presence and intensity of other sufferings. Thus, hip fracture must be studied as a biopsychosocial phenomenon, and not as a physiological event alone, since older hip fracture patients are at high risk for psychological problems related to the traumatic nature of the injury. ${ }^{39}$ Several studies of male and female hip fracture cases show low baseline QoL scores assessed by SF-36, ${ }^{40,41}$ and the high frequency of institutionalization after fracture has been well described, but there is some evidence that management approaches can reduce the number of patients who become institutionalized. ${ }^{42}$ In a long-term study, Hallberg et $\mathrm{a}^{43}$ found that health-related QoL is particularly compromised after a hip fracture when compared with other fractures, and the impact of this type of fracture is greater and prolonged, especially in the domains of PF and physical role. Furthermore, the burden of a hip fracture on self-reported health and QoL is particularly pronounced among the oldest patients. ${ }^{44}$ The World Health Organization recently recognized that in their former guidelines ${ }^{45}$ the use of drugs was overemphasized, ignoring nonpharmacological methods of pain control treatment in both acute and chronic phases. They also indicated that therapeutic regimes need to be individualized and combined with psychological support. ${ }^{45}$ Previous studies reported that depressive symptoms are associated with increased risk of disability or physical impairment, ${ }^{46,47}$ and with poorer QoL. ${ }^{48}$ In a population of hip fracture patients, the 
psychosocial factors play a main role in recovery. ${ }^{10,49}$ In fact, the prevalence and effect of psychiatric illness on outcomes in older adults with hip fractures has been widely studied by Holmes and House, ${ }^{50}$ and they confirmed that psychiatric illness, such as depression and delirium, result in increased mortality and dependence and decreased skills in activities of daily living, underlying the importance of psychiatric interventions in orthopedic wards.

A good QoL is not considered a luxury anymore, but it is regarded as a right and a primary target in every successful treatment (as modern World Health Organization guidelines prescribe), and this is especially true in elderly traumatized patients. It is an obsolete and wrong conception that treatment ends with the surgical procedure and physical rehabilitation, because a patient's psychological status plays a critical role in regaining good performance levels. Since the target of a successful treatment is the long-term success, next to technical and scientific progresses of surgery, of pain management and rehabilitation, it is mandatory to plan strategies that aim to improve QoL. Since health-related QoL should be considered a primary goal in every medical and surgical treatment, a multimodal approach that includes counseling provides an opportunity to improve patients' QoL and pain management, while reducing anxiety and dealing with depression, leading to personal and social benefits. This knowledge may help to optimize treatments in elderly patients with hip fracture.

Finally, a brief discussion on the statistical methods used is required. It should be pointed out that our results are strictly connected to the cluster analysis; cluster analysis is an exploratory data analysis tool for solving classification problems. Its object is to sort cases (people, things, events, and so on) into groups, or clusters, so that the degree of association is strong between members of the same cluster and weak between members of different clusters. It is a discovery tool that may reveal associations, patterns, relationships, and structures in masses of data which, though not previously evident, nevertheless are sensible and useful once found, so we used it to identify hidden categories of patients.

This study has some limitations due to the involvement of a relatively small number of patients. It should be considered a pilot study, designed with the main target of evaluating whether the multimodal approach, which includes counseling, is suitable for further investigation. A larger sample size will be considered in order to improve the power and significance level of the research, as well as to reduce biases. In addition, the sample size was calculated before performing the cluster analysis, and this had the consequence of a small number of cases in one of the clusters.

\section{Conclusion}

Even if long-term follow-up studies are necessary to evaluate whether good early results are sustained over a longer period, our data suggest that counseling can be useful in elderly patients with hip fracture; these patients seem to need emotional support in addition to pain treatment. Therefore, humanistic therapy, based on empathy and total acceptance, is helpful and effective.

\section{Author contributions}

$\mathrm{MG}, \mathrm{GC}, \mathrm{AD}, \mathrm{MD}, \mathrm{LM}, \mathrm{AB}$, and ADC conceived the study, participated in its design and coordination, and helped to draft the manuscript. GC and DD performed statistical analyses. SI, DD, and AM participated in the design of the study, collected data, and performed tests. All authors were involved in drafting the article or revising it critically for important intellectual content. All authors read and approved the final manuscript.

\section{Disclosure}

The authors report no conflicts of interest in this work.

\section{References}

1. Cummings SR, Melton LJ. Epidemiology and outcomes of osteoporotic fractures. Lancet. 2002;359(9319):1761-1767.

2. Beer C, Giles E. Hip fracture - challenges in prevention and management. Aust Fam Physician. 2005;34(8):673-676.

3. Brunner LC, Eshilian-Oates L, Kuo TY. Hip fractures in adults. Am Fam Physician. 2003;67(3):537-542.

4. Boockvar KS, Halm EA, Litke A, et al. Hospital readmissions after hospital discharge for hip fracture: surgical and nonsurgical causes and effect on outcomes. J Am Geriatr Soc. 2003;51(3):399-403.

5. Rossini M, Piscitelli P, Fitto F, et al. Incidence and socioeconomic burden of hip fractures in Italy. Reumatismo. 2005;57(2):97-102. Italian.

6. Keene GS, Parker MJ, Pryor GA. Mortality and morbidity after hip fractures. BMJ. 1993;307(6914):1248-1250.

7. Parker M, Johansen A. Hip fracture. BMJ. 2006;333(7557):27-30.

8. Moran CG, Wenn RT, Sikand M, Taylor AM. Early mortality after hip fracture: is delay before surgery important? J Bone Joint Surg Am. 2005;87(3):483-489.

9. Magaziner J, Hawkes W, Hebel JR, et al. Recovery from hip fracture in eight areas of function. J Gerontol A Biol Sci Med Sci. 2000;55(9): M498-M507.

10. Mossey JM, Knott K, Craik R. The effects of persistent depressive symptoms on hip fracture recovery. J Gerontol. 1990;45(5):M163-M168.

11. Lenze EJ, Munin MC, Skidmore ER, et al. Onset of depression in elderly persons after hip fracture: implications for prevention and early intervention of late-life depression. J Am Geriatr Soc. 2007;55(1): 81-86.

12. Holmes J, House A. Psychiatric illness predicts poor outcome after surgery for hip fracture: a prospective cohort study. Psychol Med. 2000;30(4):921-929.

13. Palmer RM. Perioperative care of the elderly patient. Cleve Clin JMed. 2006;73(Suppl 1):S106-S110.

14. Ponsford J, Hill B, Karamitsios M, Bahar-Fuchs A. Factors influencing outcome after orthopedic trauma. J Trauma. 2008;64(4):1001-1009. 
15. Schag CA, Ganz PA, Polinsky ML, Fred C, Hirji K, Petersen L. Characteristics of women at risk for psychosocial distress in the year after breast cancer. J Clin Oncol. 1993;11(4):783-793.

16. Ferrans CE, Powers MJ. Psychometric assessment of the Quality of Life Index. Res Nurs Health. 1992;15(1):29-38.

17. Aprato A, Massè A, Caranzano F, et al. Patient-perceived quality of life after total hip arthroplasty: elective versus traumatological surgery. ISRN Orthop. 2011;2011:1-6.

18. Allegrante JP, Peterson MG, Cornell CN, et al. Methodological challenges of multiple-component intervention: lessons learned from a randomized controlled trial of functional recovery after hip fracture. HSS J. 2007;3(1):63-70.

19. Shyu YI, Liang J, Wu CC, Cheng HS, Chen MC. An interdisciplinary intervention for older Taiwanese patients after surgery for hip fracture improves health-related quality of life. BMC Musculoskelet Disord. 2010;11:225.

20. Rogers CR. Client-Centered Therapy: Its Current Practice, Implications and Theory. London, UK: Constable; 1951.

21. Rogers CR. On Becoming a Person. Boston, MA: Houghton Mifflin; 1961.

22. Rogers CR. A Way of Being. Boston, MA: Houghton Mifflin; 1980.

23. Folstein MF, Folstein SE, McHugh PR. "Mini-mental state". A practical method for grading the cognitive state of patients for the clinician. J Psychiatr Res. 1975;12(3):189-198.

24. Tangalos EG, Smith GE, Ivnik RJ, et al. The Mini-Mental State Examination in general medical practice: clinical utility and acceptance. Mayo Clin Proc. 1996;71(9):829-837.

25. O'Connor DW, Pollitt PA, Treasure FP, Brook CP, Reiss BB. The influence of education, social class and sex on Mini-Mental State scores. Psychol Med. 1989;19(3):771-776.

26. Fabrigoule C, Lechevallier N, Crasborn L, Dartigues JF, Orgogozo JM. Inter-rater reliability of scales and tests used to measure mild cognitive impairment by general practitioners and psychologists. Curr Med Res Opin. 2003;19(7):603-608.

27. Apolone G, Mosconi P. The Italian SF-36 Health Survey: translation, validation and norming. J Clin Epidemiol. 1998;51(11):1025-1036.

28. Ware JE Jr. The SF-36 health survey. In: Spilker B, editor. Quality of Life and Pharmacoeconomics in Clinical Trials. Philadelphia, PA: Lippincott-Raven; 1996:337-343.

29. Spielberger CD, Reheiser EC, Ritterband LM, Sydeman SJ, Unger KK. Assessment of emotional states and personality traits: measuring psychological vital signs. In: Butcher JN, editor. Clinical Personality Assessment: Practical Approaches. New York, NY: Oxford University Press; 1995:42-58.

30. Hamilton M. A rating scale for depression. J Neurol Neurosurg Psychiatry. 1960;23:56-62.

31. Hamilton M. Development of a rating scale for primary depressive illness. Br J Soc Clin Psychol. 1967;6(4):278-296.

32. Wallenstein SL. Scaling clinical pain and pain relief. In: Bromm B, editor. Pain Measurement in Man: Neurophysiological Correlates of Pain. New York, NY: Elsevier Science Publishers; 1984:389-396.

33. Collins SL, Moore RA, McQuay HJ. The visual analogue pain intensity scale: what is moderate pain in millimeters? Pain. 1997;72(1-2): 95-97.

34. Ware JE, Kosinski M, Dewey JE, Gandek B. SF-36 Health Survey Manual and Interpretation Guide. Boston, MA: New England Medical Center, The Health Institute; 1993.

Journal of Multidisciplinary Healthcare

\section{Publish your work in this journal}

The Journal of Multidisciplinary Healthcare is an international, peerreviewed open-access journal that aims to represent and publish research in healthcare areas delivered by practitioners of different disciplines. This includes studies and reviews conducted by multidisciplinary teams as well as research which evaluates the results or conduct of such teams or health-
35. Tan PN, Steinbach M, Kumar V. Introduction to Data Mining. Boston, MA: Addison-Wesley; 2005.

36. Eisenach $\mathrm{J}$ [webpage on the Internet]. Chronic pain and depression: the proverbial chicken or the egg? Pg2a.org; 2012 [updated August 27, 2012]. Available from http://page2anesthesiology.org/2012/chronicpain-and-depression-the-proverbial-chicken-or-the-egg/. Accessed September 2, 2012.

37. Bravo L, Mico JA, Rey-Brea R, Pérez-Nievas B, Leza JC, Berrocoso E. Depressive-like states heighten the aversion to painful stimuli in a rat model of comorbid chronic pain and depression. Anesthesiology. 2012;117(3):613-625.

38. Ware JE Jr, Sherbourne CD. The MOS 36-item short form health survey (SF-36). I. Conceptual framework and item selection. Med Care. 1992;30(6):473-483.

39. Houldin AD, Hogan-Quigley B. Psychological intervention for older hip fracture patients. J Gerontol Nurs. 1995;21(12):20-26.

40. Peterson MG, Allegrante JP, Cornell CN, et al. Measuring recovery after a hip fracture using the SF-36 and Cummings scales. Osteoporos Int. 2002;13(4):296-302.

41. Randell AG, Nguyen TV, Bhalerao N, Silverman SL, Sambrook PN, Eisman JA. Deterioration in quality of life following hip fracture: a prospective study. Osteoporos Int. 2000;11(5):460-466.

42. March LM, Cameron ID, Cumming RG, et al. Mortality and morbidity after hip fracture: can evidence based clinical pathways make a difference? J Rheumatol. 2000;27(9):2227-2231.

43. Hallberg I, Rosenqvist AM, Kartous L, Löfman O, Wahlström O, Toss G. Health-related quality of life after osteoporotic fractures. Osteoporosis Int. 2004;15(10):834-841.

44. Rohde G, Haugeberg G, Mengshoel AM, Moum T, Wahl AK. Two-year changes in quality of life in elderly patients with low-energy hip fractures. A case-control study. BMC Musculoskelet Disord. 2010;11:226.

45. World Health Organization. WHO Normative Guidelines on Pain Management. Report of a Delphi Study to Determine the Need for Guidelines and to Identify the Number and Topics of Guidelines that Should be Developed by WHO. Geneva: World Health Organization; 2007. Available from: http://www.who.int/medicines/areas/quality_safety/ delphi_study_pain_guidelines.pdf. Accessed August 22, 2013.

46. Bruce ML, Seeman TE, Merrill SS, Blazer DG. The impact of depressive symptomatology on physical disability: MacArthur Studies of Successful Aging. Am J Public Health. 1994;84(11):1796-1799.

47. Geerlings SW, Beekman AT, Deeg DJ, Twisk JW, Van Tilburg W. The longitudinal effect of depression on functional limitations and disability in older adults: an eight-wave prospective community-based study. Psychol Med. 2001;31(8):1361-1371.

48. Ruo B, Rumsfeld JS, Hlatky MA, Liu H, Browner WS, Whooley MA. Depressive symptoms and health-related quality of life: the Heart and Soul Study. JAMA. 2003;290(2):215-221.

49. Mossey JM, Mutran E, Knott K, Craik R. Determinants of recovery 12 months after hip fracture: the importance of psychosocial factors. Am J Public Health. 1989;79(3):279-286.

50. Holmes JD, House AO. Psychiatric illness in hip fracture. Age Ageing. 2000;29(6):537-546.

care processes in general. The journal covers a wide range of areas and welcomes submission from practitioners at all levels, from all over the world. The manuscript management system is completely online and includes a very quick and fair peer-review system. Visit http://www.dovepress. com/testimonials.php to read real quotes from published authors. 